\title{
IMPLEMENTAÇÃO DA MODELAGEM DA INFORMAÇÃO DA CONSTRUÇÃO EM EMPRESA DE ARQUITETURA: UM ESTUDO DE CASO 1
}

\author{
IMPLEMENTATION OF BUILDING INFORMATION MODELLING IN AN \\ ARCHITECTURAL FIRM: A CASE STUDY
}

\author{
Karina Matias Coelho \\ Universidade de São Paulo (USP) \\ karina.matias@usp.br \\ Tassia Farssura Lima \\ Universidade de São Paulo (USP) \\ tsa29v@hotmail.com \\ Silvio Melhado \\ Universidade de São Paulo (USP) \\ silvio.melhado@usp.br
}

\begin{abstract}
Resumo
A modelagem da informação surge como uma evolução para o setor da construção civil na busca de integração dos agentes, potencialmente melhorando o processo de projeto. Inúmeros desafios e dificuldades apresentam-se na transição para os novos sistemas de informação e as empresas de arquitetura brasileiras, em sua maioria de pequeno e médio porte, apresentam algumas particularidades que limitam seu desempenho, tais como: recursos financeiros, humanos e tecnológicos escassos e alta dependência do grau de empreendedorismo e liderança de seus titulares. Por outro lado, as mudanças de processos internos geram impactos no desenvolvimento dos projetos e sua produtividade, na adaptação do fluxo tradicional de projeto e no treinamento, ao mesmo tempo em que exigem maior integração e colaboração, e processos padronizados. Este artigo analisa a implementação da modelagem da informação da construção e os problemas enfrentados em uma empresa de arquitetura, no primeiro projeto em que foi implementada. São apresentados os resultados parciais do estudo de caso, que farão parte da Dissertação de Mestrado da primeira autora, que demonstraram as dificuldades da empresa pela falta de planejamento estratégico orientado à implementação da modelagem, assim como impactos na gestão da empresa e necessidade de mudanças no processo de projeto.
\end{abstract}

Palavras-chave: Modelagem da informação da construção. Empresas de arquitetura. Implementação tecnológica.

\begin{abstract}
Building Information Modelling appears as an innovation to the construction sector in the search for technological innovation, promoting the integration of construction players and potentially improving the design process. There are numerous challenges and difficulties in the transition to new information systems and the Brazilian architectural firms are mostly small and midsize ones what defines their characteristics and limits their performance, such as financial, human and technological scarce, high dependence on the degree of entrepreneurship and leadership of their founders. On the other hand, issues related to the changes in the internal design processes generate numerous impacts on the design tasks and productivity, at the same time requiring
\end{abstract}

1 COELHO, K.M.; SILVA,, T.F.; MELHADO, S.. Implementação da modelagem da informação da construção em empresa de arquitetura: um estudo de caso. In: ENCONTRO BRASILEIRO DE TECNOLOGIA DE INFORMAÇÃO E COMUNICAÇÃO NA CONSTRUÇÃO, 7., 2015, Recife. Anais... Porto Alegre: ANTAC, 2015 
higher integration and collaboration, and standardized processes. This paper aims to analyse the implementation of Building Information Modelling in an architectural design firm and the problems challenged in a first project using it. The article shows the partial results of the case study that will integrate the Master Thesis of the first author, which have shown the firm's difficulties due to a lack of strategic planning oriented to BIM implementation, as well as its impacts in the design firm management and the need for changing in the design process itself.

Keywords: Building information modelling. Architectural firms. Technological implementation.

\section{INTRODUÇÃO}

O setor da construção civil no Brasil há décadas é rotulado como atrasado quando comparado a outros setores industriais, devido à sua baixa produtividade, em função, principalmente, de seu baixo nível de industrialização, elevado desperdício de materiais e reduzida qualificação da mão de obra, o que resulta também na baixa qualidade do seu produto final. Recentemente, o desenvolvimento das tecnologias de informação e comunicação (TICs) apareceu como alternativa para criação de novos processos capazes de incrementar o desempenho das empresas. Considera-se que o uso de TICs tem grande potencial para implementar melhorias na produtividade e competitividade do setor da construção (NASCIMENTO E SANTOS, 2001 apud ABAURRE, 2013). No cenário mundial, observa-se o crescimento do uso da Modelagem da Informação da Construção; diversos países vêm investindo em políticas nacionais de incentivo à sua implementação e a mudança tecnológica, em muitos casos, foi iniciada pelo incentivo de políticas públicas, sendo criados guias e normas que norteiam os novos processos (WONG, 2010).

No Brasil, o uso da Modelagem da Informação da Construção começou a se estabelecer nas grandes construtoras e incorporadoras no Brasil em 2007, quando algumas empresas do setor privado se mobilizaram para sua implementação (SOUZA et al, 2013). A partir do projeto piloto da Gafisa, que em 2011 implementou a tecnologia em cinco empreendimentos e contou com 65 projetistas envolvidos, outras empresas tais como Tecnisa, JHSF, SINCO e Odebrecht iniciaram seu processo de implementação (NAKAMURA, 2013). Após essas primeiras iniciativas, o setor público também passou a demandar projetos utilizando a tecnologia de modelagem com a adesão da Petrobras, CPTM, Metro, DNIT e Infraero. A partir disso, outras ações de estímulo surgiram nos últimos dois anos. Destaca-se o papel da AsBEA (Associação Brasileira de Escritórios de Arquitetura) com o lançamento em 2013 do "Guia AsBEA de Boas Práticas em BIM: Fascículo I". Também o Sinaenco (Sindicato Nacional das Empresas de Arquitetura e Engenharia Consultiva) iniciou um Ciclo de Palestras para a conscientização das empresas de projeto e introdução dos conceitos de modelagem; e, na ABRASIP (Associação Brasileira de Engenharia de Sistemas Prediais), pode-se destacar o avanço dos projetistas que usam uma plataforma de GETBIM Gerenciamento de Especificações e Tecnologias para Objetos BIM, para uniformizar as informações dos seus trabalhos.

Sob as novas demandas do mercado e o incentivo dos demais agentes da cadeia produtiva as empresas de projeto passaram a reagir a essas demandas de seus contratantes e a planejar métodos de implementação da nova tecnologia. As empresas de projeto de arquitetura, pequenas empresas em sua grande maioria, têm características diferentes quando comparadas a empresas de maior porte principalmente, em relação à sua gestão. $\mathrm{A}$ empresa deverá viabilizar a inovação como estratégia de negócio e avaliar o retorno do investimento a curto e longo prazo. O custo elevado na implantação da modelagem é apontado como uma das principais dificuldades. Estes altos investimentos estão relacionados a compra de licenças de softwares e de novos equipamentos e ao treinamento da equipe (SOUZA,2009)

O processo de projeto sofrerá grandes mudanças em todas as etapas de projeto desde a concepção ao detalhamento final do produto. Há necessidade de análise dos processos tradicionais e revisão dos seus métodos de trabalho, reorganização de equipes e 
estabelecimento de novas lideranças e responsabilidades. É necessário encontrara maneiras de continuar a produção interna de projeto enquanto simultaneamente se implementa a nova tecnologia em projetos piloto.

Implementar BIM efetivamente requer significativas mudanças na maneira de trabalhar em quase todos os níveis dentro do processo do empreendimento; não é suficiente apenas o aprendizado de novos softwares; deve haver também a reinvenção do fluxo de trabalho, treinamento da equipe e atribuição de novas responsabilidades (ARAYICY et al, 2011).

\section{GESTÃO DAS EMPRESAS DE PROJETO}

\subsection{Análise do Setor: Empresas de Projeto}

Na Construção Civil Brasileira, o setor de projetos caracteriza-se por ser composto de empresas de micro e pequeno porte. Em 2011, havia 52.657 empresas ativas no setor (SINAENCO, 2011), sendo que $84,91 \%$ das empresas possuíam de zero a quatro vínculos ativos - ou seja, profissionais contratados. Em geral, são empresas uniprofissionais que trabalham para clientes privados ou como subcontratadas de empresas maiores em contratos com o setor público. Este quadro ocorre devido a diversos fatores: inconstância da demanda por serviços, pois eles estão diretamente ligados à conjuntura econômica e política; baixo valor de mercado do produto projeto; desagregação da classe de projetistas, que não se organiza para negociar em bloco (CAMBIAGHI, 2003 apud OLIVEIRA, 2005).

Grilo (2002) afirma que a sobrevivência dos escritórios de projeto demanda a antecipação das tendências e conversão dos desafios em fontes de vantagens competitivas e oportunidades de negócio. Aponta quatro aspectos fundamentais para a obtenção de vantagens competitivas: gerenciais, mercadológicos, organizacionais e tecnológicos. Este último, ressaltado como um dos principais ativos da empresa e um de cunho estratégico.

Segundo Oliveira (2005), as pequenas empresas desempenham um papel de fundamental importância no crescimento e maturação da economia; elas, porém, apresentam algumas características particulares que limitam seu desempenho, tais como: recursos financeiros, humanos e tecnológicos escassos, alta dependência do grau de empreendedorismo e liderança de seus titulares; atuação dos seus proprietários tanto na gestão técnica como administrativa. Considerando-se que a correlação entre o desempenho do processo de projeto e o ambiente no qual é produzido - a empresa de projeto - é fundamental para garantir a qualidade dos produtos e serviços oferecidos pelas empresas, esse autor propõe um modelo de gestão para pequenas empresas de projeto, adaptado às suas peculiaridades. São evidenciados algumas oportunidades e alguns obstáculos para essas pequenas empresas que são motores ou barreiras à implementação de novas tecnologias.

Como barreiras, Oliveira apresenta a dificuldade de acesso às ferramentas de ponta da tecnologia da informação e técnicas modernas de gestão, bem como a dificuldade de atingir eficazmente o mercado com pouquíssimos recursos. São apresentados dados sobre os principais motivos de mortalidade das micro e pequenas empresas: $90 \%$ são atribuídos à não utilização de recursos de informática.

Como oportunidades, o mesmo autor salienta a produção em pequenas séries, que gera maior potencial de responder às oportunidades rapidamente e atender a mercados pequenos e especializados. A flexibilidade da pequena empresa, aliada à sua natural predisposição para inovações, permite que ela seja agente de mudanças, proporcionando o aparecimento de novos serviços e produtos. 


\subsection{Empresas de Projeto e Implementação da Modelagem da Informação}

A implementação da modelagem da informação da construção nas empresas de projeto pode permitir maior competitividade dentro de seu setor e garantir sua sobrevivência, já que o investimento em novas tecnologias da informação permitiria a realização das operações cotidianas mais rapidamente a um custo mais baixo.

Segundo Farina (2014), na implementação do BIM por uma empresa de projeto podem ser destacados dois desafios: aqueles decorrentes da mudança tecnológica e aqueles relacionados à mudança conceitual da forma de produção dos projetos. Os desafios relacionados à tecnologia são menos complexos, mas são sentidos imediatamente pelas empresas, por tocarem no aspecto econômico. As mudanças ligadas à forma de trabalho devem ser observadas com maior cautela, geram reflexões sobre o negócio e permitem agregar valor aos produtos atuais. Dessa forma, a implementação de novas tecnologias deve fazer parte do planejamento estratégico elaborado pela empresa, prevendo os custos apropriados ao investimento e calculando seu retorno a curto, médio e longo prazo.

Esse planejamento deve ser ainda mais acurado considerando que os recursos financeiros, humanos e tecnológicos são mais escassos no caso de pequenas empresas. Todas as áreas das empresas sofrerão mudanças e deverão ser avaliadas ou reavaliadas no momento da implementação da modelagem da informação da construção: estrutura organizacional, gestão comercial, gestão financeira, recursos humanos, sistemas de informação, gestão de projetos.

\section{IMPLEMENTAÇÃO DA MODELAGEM DA INFORMAÇÃO}

\subsection{Iniciativas}

De acordo com Wong (2010), a modelagem da informação da construção está expandindo sua implementação em vários países. Os autores apresentam uma revisão do processo de implementação em seis diferentes países, demonstrando que as iniciativas de implementação partiram tanto dos setores públicos quanto dos privados, como é o caso de Hong Kong. No período de 2007 a 2009, a maioria dos países estabeleceu iniciativas de determinação de diretrizes para implementação da modelagem da informação da construção que resultaram na produção de guias e manuais. Como demonstra Succar (2009), esses guias foram desenvolvidos na Austrália, Dinamarca, Finlândia, Holanda, Noruega, Estados Unidos e Europa, demonstrando amadurecimento no uso da modelagem e sua aplicação.

No Brasil, de acordo com Souza et al (2013), observa-se desde 2007 um início de movimentação no setor privado para a implementação da modelagem da informação da construção. De acordo com matéria da Revista Construção Mercado as grandes construtoras e incorporadoras brasileiras iniciaram uma série de projetos-piloto para avaliar a aplicabilidade do BIM, na busca de aumento de produtividade, redução de perdas, diminuição de prazos, melhoria nos orçamentos e melhoria na qualidade do produto imobiliário. (DELATORRE, 2014). Em 2011, de acordo com a revista AU (REIS, 2011), quatro empresas de projeto de arquitetura, de diferentes portes, demonstraram alguns resultados das suas implementações no período de 2004 a 2007. Foram relatadas as primeiras experiências, dificuldades, ganhos e algumas recomendações. Pode ser destacado como ação especifica para as empresas de projeto de arquitetura o "Guia AsBEA de Boas Práticas em BIM". O fascículo 1 foi lançado em 2013 com instruções sobre o uso de ferramentas digitais nos projetos de arquitetura e toda a cadeia produtiva da construção civil. Este primeiro fascículo aborda as fases conceituais e iniciais de implementação do BIM e os demais fascículos ainda estão em desenvolvimento.

Implementar BIM efetivamente requer significativas mudanças na maneira de trabalhar em 
quase todos os níveis dentro do processo do empreendimento; não é suficiente apenas o aprendizado de novos softwares; deve haver também a reinvenção do fluxo de trabalho, treinamento da equipe e atribuição de novas responsabilidades (ARAYICY et al, 2011). Além disso a utilização da tecnologia na prática é uma decisão de negócio, pois a rotina de trabalho de uma empresa vai requerer mudanças de processos (JERNIGAN, 2008).

Arayici (2011) indica quatro estágios para a implementação da mudança tecnológica:

1) Diagnóstico: revisão detalhada e análise das práticas correntes;

2) Plano de Ação: novos processos de negócio e caminhos para adoção da tecnologia;

3) Ação: Implementação da Modelagem da Informação da Construção;

4) Avaliação: Revisão do plano, disseminação e integração ao planejamento estratégico.

Succar (2009) afirma que as empresas que decidem atravessar o abismo da inovação e investir em aplicações BIM se tornarão empresas inovadoras, como demonstra figura. Esse autor em seu BIM Maturity Index (BIMMI) define cinco níves de maturidade para a adoção da nova tecnologia: (a) Inicial/ Ad-hoc, (b) Definido, (c) Gerenciado, (d) Integrado, (e) Otimizado. Afirma que, em geral, o progresso do nível mais baixo ao mais alto indica: melhor controle por meio da diminuição de variações entre metas e resultados reais, uma melhor previsibilidade baixando variabilidade na competência, desempenho e custos, uma maior eficácia no alcance de metas definidas e estabelecimento de novas metas mais ambiciosas. De acordo com Jensen e Jóhannesson (2013), o mais importante no processo de implementação parece ser a condução da transformação em pequenos passos. A parte de recursos humanos na transformação para o "pensamento em BIM" pode ser muito difícil. É natural que alguns se sintam ameaçados pelas mudanças. Isso, por si só, pode ser visto como uma boa razão para as empresas implementarem o BIM em pequenos passos. Os resultados obtidos por esses autores mostram a importância do envolvimento do gestor do projeto na implementação, pois a liderança deve estar convicta dos benefícios do BIM, que deve ser visto como elemento principal do negócio e não apenas como mais um conjunto de softwares. Se uma empresa quer implementar BIM, isso significa que mudanças fundamentais são necessárias em todos seus processos. O período de transição dos processos tradicionais para os processos baseados em BIM é crítico para todas as empresas e tem que ser executado com atenção aos interesses próprios de cada organização. É imprescindível difundir o conhecimento para todos os colaboradores, de modo a torná-los conscientes dos potenciais desses novos processos.

\subsection{Desafios, Dificuldades e Barreiras}

Em pesquisa apresentada por Eadie (2013), as principais razões para não implementação da modelagem da informação foram a falta de conhecimento da tecnologia dentro da equipe de projeto e dentro das organizações. Na sequência, outras razões foram apontadas: falta de demanda dos clientes, resistência cultural, alto investimento financeiro, falta de financiamento adicional que suporte a modelagem, resistência no nível operacional, relutância dos membros da equipe em compartilhar informação, falta de benefícios imediatos nos projetos. Nessa mesma pesquisa, foi indicado como maior impacto do uso da modelagem a colaboração entre os agentes, relatada como chave para seu sucesso. Em segundo lugar foi destacada a afirmação de que a modelagem da informação é mais um processo do que uma tecnologia. Checcucci e Amorim (2011) afirmam, a partir dos resultados das análises de dados coletados durante o TIC 2011, que, entre as maiores dificuldades na adoção do BIM, estão a cultura, a resistência e o medo de mudanças. Segundo Wong (2011), para atingirem sucesso na implementação, os esforços em direção a tecnologia, pessoas e processos devem ser equivalentes. Souza (2009) identificou em pesquisa realizada com 13 empresas de projeto de arquitetura algumas barreiras à 
implementação da modelagem da informação. Os principais motivos alegados foram a resistência à mudança do software pela equipe $(25 \%)$ e a falta de tempo para a implementação. De acordo com Gu (2010), os fatores que afetam a adoção do BIM podem ser divididos em dois grupos principais: as questões técnicas e as questões não técnicas. $O$ autor relata uma série de fatores identificados na literatura como principais barreiras para a adoção do BIM: falta de sensibilização e formação; natureza fragmentada do setor de AEC; relutância da indústria para mudar a prática de trabalho; hesitação para aprender novos conceitos e tecnologias; falta de clareza sobre papéis, responsabilidades e distribuição de benefícios. Esse último autor ressalta que uma padronização de processos e protocolos é necessária para garantir responsabilidades e conduzir as análises de projeto e validações. Arayici (2011) demonstra que a empresa de arquitetura JMA (Jonh McCall's Architects), usando ferramentas 2D CAD por duas décadas, enfrentou diversas dificuldades, tais como: pressões por prazos, duplicações de informações, prazos de entrega longos, falta de continuidade na cadeia produtiva, produção excessiva, retrabalho, distrações com tarefas paralelas, falta de confiabilidade dos dados, falta de processo de projeto rigoroso, falta de eficácia na gestão e comunicação.

\section{O PROCESSO DE PROJETO DE ARQUITETURA}

Segundo Melhado (1994), o papel do projeto é desenvolver, organizar, registrar e transmitir as características técnicas e geométricas do produto para serem utilizadas em sua execução. Ou seja, é uma representação das características do edifício e de seus processos construtivos que serão interpretados na fase de construção. O Manual de Escopo de Projetos e Serviços da Arquitetura e Urbanismo (AsBEA, 2003) caracteriza o processo de projeto de arquitetura, definindo uma sequência de atividades, distribuídas por seis fases, que estão relacionadas àquelas estabelecidas pela NBR 15.531: a) Fase A - Concepção do Produto: Levantamento de dados, Programa de Necessidades e Estudo de Viabilidade; b) Fase B - Definição do Produto: Estudo Preliminar, Anteprojeto, Projeto Legal; c) Fase C Identificação das interfaces: Projeto Básico; d) Fase D - Detalhamento dos projetos: Projeto Executivo; e) Fase E - Pós-entrega do projeto; f) Fase F - Pós-entrega da obra.

$\mathrm{O}$ projeto de arquitetura tem características particulares em seu desenvolvimento, com uma grande ênfase nas suas etapas iniciais, que envolvem viabilidade e concepção. O uso de softwares $3 \mathrm{D}$ é uma prática comum entre os arquitetos nestas etapas de projeto, estando estes profissionais familiarizados com a visualização dos seus projetos em três dimensões. $O$ uso da modelagem da informação, porém, pode exigir novos processos na medida em que existe a necessidade de interoperabilidade entre os softwares de concepção e os softwares de modelagem que darão continuidade nas etapas de projeto subsequentes. Todo o processo de projeto poderá sofrer alterações com a aplicação de novas tecnologias da informação, demandando antecipação de informações ou sobreposição de etapas.

De acordo com Abaurre (2013), a modelagem da informação da construção foi introduzida com o intuito de implementar um processo de projeto colaborativo e integrado. A antecipação de atividades e decisões nos processos colaborativos da modelagem da informação da construção leva à simultaneidade dos projetos com trabalhos de engenharia de planejamento e de controle de qualidade. Essa característica aumenta a quantidade de informações geradas nas etapas iniciais, diferenciando-se dos acertos comerciais tradicionais comumente praticados, em que as maiores parcelas de pagamento são associadas às etapas finais do projeto, quando ocorre o detalhamento e levantamento de quantitativos.

A edição 248 da revista AU (REIS, 2011) apresenta o caso de quatro empresas de arquitetura que adotaram a modelagem da informação. É relatado que uma das mudanças importantes constatadas foi a alteração no prazo das etapas do projeto. No processo 
convencional, a carga de trabalho do arquiteto seria menor nos estudos preliminares e aumentaria conforme o projeto se aproxima do executivo. No BIM, algumas informações técnicas precisam ser definidas em etapas anteriores ao usual e tal curva se inverte; decisões são antecipadas e uma carga maior de trabalho é deslocada para o anteprojeto.

O combustível do projeto são as informações. Os projetistas usam e produzem informações na forma de ideias, princípios, regras e habilidades, aplicados para gerar uma descrição abstrata (MANZIONE, 2013). Essa afirmação se torna mais importante no contexto da modelagem da informação. Os primeiros modelos que serão utilizados e incrementados durante todo o ciclo de vida da edificação, são iniciados pelas empresas de projeto. Cada informação adicionada em um modelo BIM poderá ser utilizada do projeto até a fase de operação do empreendimento (FARINA, 2014). Essas informações serão utilizadas por diversos agentes da cadeia de diferentes maneiras e com abordagens distintas. As informações dos objetos serão atribuídas de acordo com o estágio de projeto (SOUZA, 2009 apud KYMMEL, 2005) e de acordo com nível de detalhamento estipulado para o modelo.

Algumas pesquisas demonstram que o uso mais frequente da modelagem acontece nos estágios finais de projeto e de pré-construção (EADIE,2013). Dessa forma, ainda que consideradas um elo mais fraco em comparação aos outros agentes da cadeia produtiva da construção civil, as empresas de projeto têm um importante papel no processo de adesão à modelagem de informação e o investimento na qualidade da implementação da tecnologia nessas empresas poderá beneficiar todo o setor, assim como poderá ser um propulsor da adesão da modelagem por outros agentes da cadeia produtiva.

\section{ESTUDO DE CASO}

\subsection{Metodologia}

Para cumprir os objetivos propostos nesta pesquisa foi adotado o método de estudos de caso. Propôs-se uma pesquisa qualitativa por ser apropriada quando o fenômeno em estudo é complexo, de natureza social e que não tende à quantificação; e por ser útil para observar, registrar e analisar interações reais entre pessoas, e entre pessoas e sistemas (MORESI, 2003). O objetivo deste artigo é demonstrar os resultados iniciais da implementação da modelagem da informação na empresa de arquitetura, objeto do estudo de caso. Serão analisados os impactos da adoção da modelagem em níveis organizacionais que se referem à gestão da empresa e no processo de produção abordando tanto as questões tecnológicas como as de desenvolvimento de projetos de arquitetura.

As informações a respeito da implementação nesta empresa foram obtidas a partir da experiência profissional da autora neste processo, durante três meses, com permanência na empresa durante dois dias da semana. Também forma realizadas entrevistas com 0 gerente, coordenadora e equipe de arquitetos.

\subsection{Caracterização da Empresa}

A empresa de projeto de arquitetura analisada é franco-brasileira e tem sua base em São Paulo, desde 2000, e em Paris, desde 2008. Atua em projetos de arquitetura e de design de interiores, para diversos segmentos de construção, tais como residências, edifícios comerciais e residenciais, hotéis e retrofit, no Brasil e na França.

Destaca-se em seu ramo de atuação por variadas publicações e premiações de seus projetos, incluindo exposições em Bienais. Seu quadro de colaboradores conta com quatro arquitetos titulares e uma equipe de aproximadamente 50 contratados. A área de gestão é composta por sete pessoas: um coordenador geral, dois desenvolvedores de negócios, um 
gestor financeiro, um gestor de marketing e comunicação, um gestor comercial e uma secretária. $\mathrm{O}$ restante da equipe é composto por arquitetos e estagiários de arquitetura. A empresa não possui organograma formal e os arquitetos titulares se revezam na coordenação das equipes de projeto.

\subsection{Caracterização do Caso}

O investimento previsto é de 1,4 bilhões de reais, para uma área total do empreendimento de $140.525,00 \mathrm{~m}^{2}$, divididos entre atividades de restauro e construção de duas novas edificações, além da criação de subsolos. Os projetos tiveram início em 2009 e foram concebidos por uma empresa de arquitetura francesa. Após a concepção, o projeto passou para uma primeira empresa de arquitetura brasileira, responsável por ele até 2014. Nesse período foram realizados os trâmites legais, envolvendo as aprovações nos órgãos competentes. O processo foi demorado, pois a área é tombada pelo Condephaat e Compresp, órgãos estadual e municipal, respectivamente. A cargo da empresa de arquitetura, objeto deste estudo de caso, ficaram as duas construções novas: um edifício de vinte três andares de uso misto - flats, hotel e andares de escritório e oito subsolos com área construída de $36.321,72 \mathrm{~m}^{2}$; e outro, para uso comercial, com seis andares e área aproximada de $10.000 \mathrm{~m}^{2}$. O projeto ainda inclui uma edificação a ser preservada com área aproximada de $16.300,0 \mathrm{~m}^{2}$ e oito andares novos de subsolos com $36.508,63 \mathrm{~m}^{2}$.

Os trabalhos iniciaram-se na empresa estudada em janeiro de 2015. Este projeto havia passado anteriormente por outras empresas de arquitetura, que iniciaram sua concepção e suas primeiras etapas de anteprojeto. $O$ porte do projeto exigiu a montagem de uma equipe especialmente dedicada para desenvolvê-lo, localizada em uma sala à parte das demais equipes. Uma equipe inicial de quatro arquitetos, coordenados por um gerente, iniciou a revisão geral da etapa de anteprojeto, ainda em plataforma CAD 2D, com o objetivo de atender às novas demandas do cliente. Até a data de elaboração deste artigo a equipe já contava com nove arquitetos, uma coordenadora e um gerente de projeto.

\subsection{Implementação da Modelagem da Informação}

A implementação da modelagem ocorreu a partir da exigência de uso da tecnologia solicitada pelo cliente e foi essencial para que pudessem ganhar a concorrência frente aos seus concorrentes. É importante salientar que este é o primeiro projeto da empresa utilizando a modelagem da informação da construção e não havia experiências anteriores da empresa em nenhuma de suas equipes. A empresa utilizava CAD 2D, além de outros softwares 3D tais como SketchUp e 3D Studio Max.

Sendo assim, existia pouco embasamento teórico sobre as dificuldades e as potencialidades da implementação da modelagem. Em entrevistas com cada membro da equipa, foi identificado que possuíam diferentes níveis de conhecimento dos softwares de modelagem. $\mathrm{Na}$ equipe inicial composta por quatro arquitetos, dois estavam em fase de conhecimento básico, um havia participado de um projeto em fase de anteprojeto e um possuía experiência em vários projetos, da concepção ao executivo. A coordenadora havia passado por um treinamento inicial, mas nunca havia participado de um projeto que utilizasse modelagem. O gerente possuía experiência anterior com projetos feitos em softwares de modelagem diferentes do adotado e reconhecia algumas dificuldades e alguns benefícios, apoiando durante todo o processo o uso exclusivo do software de modelagem em detrimento do CAD 2D.

No início do projeto, foi contratada uma consultoria com o objetivo de assegurar que a modelagem fosse aderente às necessidades do cliente e para potencializar a produção do projeto, que ainda continuava a ser desenvolvido parcialmente em CAD 2D. Coube à 
consultoria o papel de começar a modelagem, estabelecendo alguns padrões de trabalho e estabelecendo novos processos para a equipe de trabalho. Também foram necessários, nessa etapa, alguns treinamentos complementares do uso de funcionalidades do software para o trabalho colaborativo, feitos in loco. A implementação acabou ocorrendo em paralelo ao processo de produção do projeto, gerando demandas conflituosas em momentos críticos de entregas parciais do trabalho.

\subsection{Gestão da Empresa}

Para este projeto houve investimento inicial, tanto em treinamento da equipe, quanto para compra de licenças de software. Também foi necessário comprar computadores para todos os membros da equipe, pois os computadores existentes não suportavam o novo software. Todo o investimento foi feito em fases, devido ao seu alto custo. Num primeiro momento parte da equipe ainda utilizava computadores ultrapassados que dificultavam o desenvolvimento do trabalho. Houve também necessidade de contar com um servidor exclusivo. Uma equipe de produção de dez pessoas acessa e sincroniza seu trabalho simultaneamente em dois arquivos centrais. A quantidade de acessos a documentações e 0 trabalho colaborativo com o software de modelagem exigiu esse investimento.

Houve mudanças na estrutura da empresa, sendo necessário a parceira com uma segunda empresa de projetos que assumiu a gerência do projeto e todo o contato com o cliente. Um dos sócios acompanha o desenvolvimento do trabalho junto ao gerente. A nova equipe, montada especialmente para esse projeto e alocada em sala a parte do restante da produção também demonstra mudança estrutural na empresa, tanta em recursos tecnológicos como em recursos humanos.

No que se refere aos recursos humanos, tornou-se necessária uma nova forma de seleção e foi relatada a dificuldade para encontrar profissionais qualificados, tanto em projeto quanto na nova tecnologia. Identificou-se, após o primeiro mês, a necessidade de contratação de uma coordenadora de projetos e mais quatro arquitetos e, assim, a equipe inicial de produção, de quatro pessoas, foi crescendo ao longo do projeto. O nível de conhecimento da equipe do software de modelagem era bastante heterogêneo com relação a experiência de utilização da ferramenta, tornando necessárias muitas adaptações e novas divisões de tarefas, que impactaram diretamente o desenvolvimento do projeto.

\subsection{Processo de Projeto}

O processo de projeto da empresa seguiu parcialmente o modelo sugerido pelo Manual de Escopo de Projetos de Arquitetura. A modelagem do projeto iniciou-se na Fase C - Projeto Básico com a inserção dos arquivos $2 \mathrm{D}$ produzidos na fase anterior (Fase $B$ - Definição de Produto: Anteprojeto). O objetivo era modelar o projeto de modo que ficasse no mesmo nível de detalhamento desta etapa. Das etapas anteriores a equipe possuía plantas, cortes, elevações em .dwg e um modelo de estudo preliminar de arquitetura em formato .skp. Este modelo, junto as demais documentações do projeto, auxiliavam a equipe a compreender o projeto como um todo. É importante lembrar que a concepção do projeto não foi elaborada pela empresa, portanto estavam em constante contato com os arquitetos de concepção para aprovar alterações e fazer novas definições.

A equipe de consultoria teve pouco tempo para criar procedimentos e metodologias de trabalho antes de se iniciar a modelagem. Lentamente, dois arquitetos da equipe passaram a produzir pequenas partes do modelo. A maior parte do tempo da equipe inicial (de quatro arquitetos) ainda se concentrava em atender novas solicitações dos clientes e evoluir o projeto para que outras equipes de projetos de Engenharia pudessem desenvolver seus trabalhos. Simultaneamente, eram desenvolvidos a modelagem e a documentação 2D em 
softwares diferentes, gerando conflitos nos cronogramas internos e sobreposições. Coube à equipe de consultoria o desenvolvimento da maior parte da modelagem, ainda que estivesse defasada do projeto que seguia sendo modificado em .dwg.

A interação com o projeto de estruturas deu-se inicialmente por meio de croquis desenvolvidos pelo projetista e pelos arquitetos para definição de soluções de projeto. Foi utilizado também um arquivo .skp, modelado pela empresa anterior de projeto de arquitetura. A complexidade do projeto de estruturas exigia visualizações em três dimensões para que as decisões da equipe fossem facilitadas.

O projetista de estrutura também disponibilizou um arquivo iff, desatualizado quanto às últimas decisões de projeto, que foi inserido no modelo de arquitetura para poucas análises. Essa interação foi importante para a equipe conhecer alguns conceitos básicos da modelagem da informação. As interações entre as equipes de estrutura e arquitetura ainda aconteciam em reuniões presenciais e eram baseadas em croquis parciais feitos tanto pelos projetistas de estruturas como pelos de arquitetura e em impressões de desenhos parciais do modelo do SkechtUp, com anotações e croquis. Até a finalização deste artigo, a concepção do projeto de estruturas das três edificações não havia sido finalizada, assim como não havia ocorrido nenhuma entrega formal de plantas e cortes do projeto.

Os projetos de sistemas prediais (hidráulica, elétrica e ar condicionado) estavam em fase de estudo preliminar, com definições iniciais de shafts e espaços técnicos. Esses projetistas não serão responsáveis pela modelagem de seus projetos; para esse trabalho, uma terceira empresa foi contratada para modelar os sistemas em paralelo ao seu desenvolvimento, ao mesmo tempo em que será responsável pela coordenação e compatibilização 3D de todos os projetos. Até a finalização deste artigo, esse trabalho não havia sido iniciado.

O projeto contava também com uma empresa externa responsável pela coordenação geral das equipes, que realiza toda a comunicação com o cliente. Semanalmente, reuniões gerais de projeto são realizadas, contando com a participação de todas as equipes de projeto.

\section{ANÁLISE CRÍTICA DO CASO ESTUDADO}

Com relação à gestão da empresa, como ressalta a bibliografia consultada, ainda que com dificuldade, a conversão do desafio em oportunidade e a antecipação da tendência tecnológica trouxe uma vantagem competitiva para a empresa, possibilitando sua contratação para um projeto de relevância. A bibliografia também aponta que 0 planejamento de pequenas empresas deve ser ainda mais acurado, considerando os escassos recursos financeiros, humanos e tecnológicos e que o investimento em pessoas e tecnologia deve ser equivalente, para garantir que os objetivos do projeto e da empresa sejam atingidos. Nesse sentido, algumas dificuldades foram detectadas:

- Os custos apropriados ao investimento para troca de todos os computadores e compra das licenças de softwares não foram planejados;

- Novo planejamento interno com alocação da equipe em espaço ainda não adaptado às novas necessidades - além dos computadores, foi necessário novo mobiliário, novas instalações de infraestrutura e o direcionamento de um dos servidores para atender demandas especiais da equipe. Todas essas mudanças aconteceram simultaneamente à produção do projeto, que já encontrava dificuldades e causou transtorno e replanejamentos diários para a equipe já sobrecarregada;

- Ao longo do desenvolvimento do trabalho, foi identificada a necessidade de novas contratações para garantir os prazos de entrega e a produtividade esperada. Durante a primeira fase foram contratados cinco novos arquitetos e uma coordenadora. As contratações aconteciam ao mesmo tempo em que o trabalho era desenvolvido e 


\section{$\pi$}

cada novo membro tinha pouco tempo para entender e se adaptar ao processo. Como consequência, erros e perdas de produção por falta de treinamento.

- A seleção de profissionais não reduziu a grande heterogeneidade de conhecimento sobre modelagem entre os membros da equipe: alguns tinham pouca experiência e necessitavam de ajuda constante dos colegas, prejudicando o desenvolvimento do trabalho. A gerência e a coordenação também tinham dificuldades em delegar tarefas aos novos membros, por não conhecerem sua capacitação.

Com relação à implementação da modelagem não foram realizadas as etapas de diagnóstico e plano de ação que seriam necessárias, segundo a bibliografia consultada, para permitir o alinhamento com os objetivos de negócio e com as práticas correntes na empresa, para avaliar os riscos envolvidos e delimitar uma abordagem sistemática para a implementação. Também é sugerida pela bibliografia a condução da transformação em pequenos passos. A falta dessa abordagem apresentou impactos desde as etapas iniciais do trabalho, tais como:

- A dificuldade de gestão da equipe, subdividida em modelagem e CAD 2D, resultando em retrabalho, pressões por prazos e duplicação de informações. Não havia clareza sobre papéis e responsabilidades criadas a partir da implementação da modelagem;

- Resistência dos membros da equipe em assumir a modelagem, por inseguranças com relação aos novos processos e a tecnologia. Coube à consultoria a maior parte da modelagem e por um período de aproximadamente dois meses os arquitetos atuaram como "assistentes de projeto" da consultoria;

- Inexistência de análise prévia dos processos criados pela introdução da modelagem e inexistência de padronizações de processos e protocolos;

- Falta de conhecimento dentro da organização, já que se tratava do primeiro projeto da empresa, com deficiências na gestão e comunicação interna. A diretoria não estava a par das dificuldades diárias enfrentadas pela equipe, e permanecia cobrando os resultados do projeto em prazos iguais aos esperados para o CAD 2D.

Quanto ao processo de projeto, ficou claro que é necessário não somente o aprendizado de novos softwares, mas também novo fluxo de trabalho, treinamento da equipe e atribuição de novas responsabilidades para garantir bons resultados (ARAYICY et al, 2011):

- Apesar do conhecimento de outros softwares (SketchUp, Rhynoceros) a equipe não possuía conceitos básicos de interoperabilidade, o que prejudicou a troca de informações de projeto entre os softwares e gerou análises duplicadas;

- Os processos com interface com outras empresas de projeto eram também duplicados: caso do projeto de estruturas, que era concebido sem auxílio da modelagem e com trocas de documentos em papel. Até o momento da finalização deste artigo, a resistência à mudança de processos ainda não tinha sido superada;

- A antecipação de informações para a modelagem não era esperada pela equipe e a etapa de anteprojeto exigia mais detalhamento e especificações do que quando produzida no CAD 2D. Havia dúvidas se estavam reproduzindo o Anteprojeto ou se já estavam antecipando o Pré-Executivo;

- O trabalho colaborativo, com os membros da equipe acessando um único arquivo e sincronizando as atualizações, mudou totalmente a maneira de produzir o projeto. Era necessária uma troca diária de informações, consultas e acordos para o desenvolvimento do trabalho. A gestão da equipe teria sido mais eficiente se o gerente do projeto tivesse conhecimento mais aprofundado das facilidades e dificuldades do software.

- A criação de biblioteca de componentes teve que ser simultânea a produção dos projetos; não houve tempo de preparo e de analise das necessidades do projeto. 


\section{CONSIDERAÇÕES FINAIS}

A introdução da modelagem da informação requer investimento de tempo e dinheiro, analise dos riscos e de retorno do investimento. A utilização de uma nova ferramenta gera impactos na gestão da empresa e a mudança exige a formulação de uma estratégia de implementação que ocorre simultaneamente a produção e entrega dos projetos. A abordagem adotada para a aproximação e utilização da modelagem definirá a qualidade dos resultados finais e a satisfação dos objetivos esperados. A empresa que implementa a modelagem sofre fortes impactos em sua gestão e em seu processo de produzir o projeto. $O$ planejamento estratégico da empresa deve prever custos elevados durante o período inicial e ser capaz de transformar o investimento em resultados. A necessidade de conhecimento de gestão na empresa é fundamental para evitar prejuízos e decisões arriscadas. A perda de produtividade nos estágios iniciais de aprendizado deve ser levada em consideração nos cronogramas de entregas dos trabalhos. Para isso a escolha de projetos que permitam maior tempo de produção unidos a um apoio externo, como uma consultoria, podem evitar desperdício de tempo e garantir que os resultados sejam mais rapidamente atingidos. Devese prever que durante o período de transição o uso do CAD simultâneo ao software de modelagem será uma realidade. A potencialidade após a fase de transição é a de ganho de produtividade nos projetos pela facilidade de geração de documentação de projeto. Todas as informações do projeto, conectadas a um único modelo garante a coerência das informações apresentadas ao mesmo tempo em que, uma vez que a documentação esteja montada as revisões de partes de projetos serão simultâneas em plantas, cortes e etc. A possibilidade de criação de novos produtos. Para a melhoria do uso da modelagem a escassez de políticas publicas que incentivem e de associações setoriais que promovam o uso das ferramentas e a necessidade de bibliotecas criadas por fornecedores são fatores limitantes. A falta de treinamentos adequados que promovam o conhecimento dos aplicativos em equilíbrio com os conceitos essenciais da modelagem da informação também limitam a capacidade das empresas na implantação. Quanto maior for o domínio do conhecimento de software e conceitual mais apta a empresa estará para desenvolve-se sozinha quando superados os estágios iniciais de implantação.

\section{REFERÊNCIAS}

ABAURRE, M.W. Modelos de Contrato Colaborativo e Projeto Integrado para Modelagem da Informação da Construção. São Paulo, 2013. Dissertação (Mestrado) Escola Politécnica, Universidade de São Paulo, 2013. 187p.

ARAYICI, Y., COATES P., KOSKELA, L., KAGIOGLOU, M. BIM adoption and implementation for architectural practices. Emerald Structural Survey Vol. 29 No. 1, 2011, pp. 7-25

CHECCUCCI, E. S.; PEREIRA, A. P.; AMORIM, A. L. A difusão das tecnologias BIM por pesquisadores do Brasil. In: ENCONTRO DE TECNOLOGIA DE INFORMAÇÃO E COMUNICAÇÃO NA CONSTRUÇÃO, 5., 2011, Salvador. Anais... Salvador: UFBA, 2011. CD-ROM.

DELATORRE, J. P. M., SANTOS, E. T. Introdução de novas tecnologias : o caso do BIM em empresas de construção civil. XV Encontro Nacional da Tecnologia do Ambiente Construído, 2014, Maceió. Anais...CD-ROM.

EADIE R., BROWNE M., PDEYINKA H., MCKEOWN C., MCNIFF S. BIM Implementation throughout the UK construction project lifecycle: An analysis. Automation in Construction. Vol. 36 (2013), 145151.

FARINA, H. Modelagem da Informação em Sistemas Prediais. Hydro, Abril 2014.Disponível em < http://www.arandanet.com.br/midiaonline/hydro/2014/abril/index.html>. Acesso em 05 mai 2014.

GRILO, L.M. Recomendações para a Gestão da Qualidade no Desenvolvimento de Projetos na Construção de Edifícios em Regime Contratual de Empreitada por Preço Global. 2002. Dissertação (Mestrado) - Universidade de São Paulo, 2002. 157p. 
GT BIM - Grupo Técnico BIM- ASBEA (Associação Brasileira de Escritórios de Arquitetura). Guia Asbea Boas Práticas em BIM: Fascículo 1. 2013, São Paulo.

GU, N. LONDON, K. Understanding and facilitating BIM adoption in the AEC industry. Journal Automation in Construction 19 (2010) 988-999

JENSE, P.A.; JÓHANNESSON, E.I. Building information modelling in Denmark and Iceland. Engineering, Construction and Architectural Management, Bingley, vol.20, no.1, p. 99-110, 2013.

JERNIGAN, F. BIG Bim, Little Bim: The practical approach to building information modeling. $1^{\text {a }}$ Ed., 4Site Press, Salisbury, 2007

MANZIONE, L. Proposição de Uma Estrutura Conceitual da Gestão do Processo de Projeto Colaborativo com o uso do BIM. São Paulo, 2013. Tese (Doutorado) Escola Politécnica, Universidade de São Paulo, 2013. 325p.

MELHADO, S. B. Qualidade do projeto na construção de edifícios, 1994. Tese (Doutorado) Universidade de São Paulo, São Paulo, 1994. 310p

NAKAMURA, J. Como anda o BIM nas incorporadoras. Construção Mercado, [S.I.], ed. 143, jun. 2013. Disponível em: < http://construcaomercado.kubbix.com/negociosincorporacaoconstrucao/143/artigo290692-1.aspx>. Acesso em: 10 dez. 2013.

OLIVEIRA, O. J. Modelo de Gestão para pequenas empresas de projeto de edifícios. São Paulo, 2005. Tese (Doutorado) Escola Politécnica, Universidade de São Paulo, 2005

REIS, P., Saiba como foi a implementação do BIM em escritórios de arquitetura. ed. 208,jul. 2011. Disponível em: < http://au.pini.com.br/arquitetura-urbanismo/208/desafios-da-implementacao-2243731.aspx. Acesso em: 10 dez. 2013.

SINAENCO (Sindicato Nacional das Empresas de Arquitetura e Engenharia Consultiva) Perfil do Setor de Arquitetura e Engenharia Consultiva - Edição 2013.

SOUZA, F. Diretrizes para Organização da área de projetos em empresas incorporadoras.. Em andamento. Tese (Doutorado) Escola Politécnica, Universidade de São Paulo.

SOUZA, F. WYSE, M. MELHADO, S.B. The Brazilian Design Manager Role and Responsabilities after the BIM Process Introduction. IN: CIB WBC 2013, Queensland, 2013. Proceedings Queensland: 2013

SOUZA, L.L.A. Diagnóstico do Uso de BIM em empresas de projeto de arquitetura. Niterói, 2009. Dissertação (Mestrado). Universidade Federal Fluminense, 2009.202p.

SUCCAR, B. Building Information modelling framework: A research and delivery foundation for industry stakeholders. Automation In Construction. V.18 p. 357-375.2009

WONG, A. WONG, F. Nadeem, A. Attributes of Building Information Modelling Implementations in Various Countries. Architectural Engineering and Design Management,Vol.6 N.4: 288-302, 2010. 